\title{
The Application of Computer and Fuzzy Clustering in Tourism Resources Evaluation
}

\author{
Guojing FAN \\ GanNan Normal University, GanZhou, Jingxi, 341000, China.
}

Wei ZHU* \& Jiejuan TANG

Department of Sociology, Zhejiang University, Hangzhou, Zhejiang, 310007, China

\begin{abstract}
The evaluation of tourism resources has great significance in the development of the tourism resources. This paper selects 8 indexes, including rarity, ancient, size, preciousness, preservation, beauty, combination, celebrity to evaluate tourism resources, and the weight values of the 8 indexes were determined by experts scoring. Fuzzy clustering method was used to analyze boundary value types and spatial distribution of the tourism resources. Moreover, the system software is programmed by Delphi, showing us the design ideas and methods of the software. The system was proved to be effective in the evaluation of tourism resources in China.
\end{abstract}

KEYWORD: Tourism resources evaluation; Computer; Fuzzy Clustering; MIS

\section{INTRODUCTION}

With the continuous improvement of people's living standards, Tourism is increasingly becoming an important part in people's lives. Tourism industry steps into a golden age which develops rapidly with the tourism consumption growing year after year. In recent years, many local governments treated tourism as a pillar industry to develop tourism resources. At first,to make use of tourism resources, it is essential to conduct the scientific evaluation of tourism resources. At present, there are three development trends in the methods of tourism resources evaluation: (1)to Quantify the evaluation index; (2)to model the evaluation; (3)to publicize the assessment Standard.

The evaluation method of fuzzy mathematics is widely used recently. As tourism resources with more vague and uncertain factors, it can achieve better results to use fuzzy mathematical method for classification and evaluation.

Computer is an indispensable tool in the information age, and it is widely used in data processing and management. The papers introduce an assessment system of tourism resources which is based on fuzzy clustering. The system using a fuzzy clustering technique is a system of information management and data analysis, which is specially designed for the tourism resources evaluation.

\section{THE PRINCIPLE OF TOURISM RESOURCES EVALUATION}

Tourism resources evaluation is based on tourism resources evaluation system which is concluding index system, weight value and evaluation method. We selected "eight aspects" as the evaluation index, namely, rare, antiquity, scale, peculiar, preservation, aesthetic, combination, reputation. The weight values were determined according to the importance of each index which is shown in table 1. Fuzzy clustering method was used to analyze types of boundary value, and specific assessment consists of data acquisition and data processing (that is to say, to evaluate according to assessment system). The data was acquired by investigation which treated the published records as the main basis and was supplemented by field investigation, and data processing consists of ranking, the division of boundary value levels and the analysis of boundary values etc., then the results of evaluation was given according to requirement [1].

Table 1 Weight values of evaluating index

\begin{tabular}{|c|c|c|c|c|c|c|c|c|c|c|}
\hline & $\frac{\frac{\delta}{0}}{\stackrel{0}{\Xi}}$ & $\begin{array}{l}\frac{T}{0} \\
0 \\
\frac{0}{0} \\
\bar{n} \\
\bar{n} \\
0 \\
b\end{array}$ & $\bar{E}$ & $\begin{array}{l}\sigma \\
\mathscr{0} \\
\stackrel{\Xi}{E}\end{array}$ & 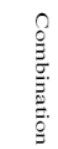 & $\frac{n}{N}$ & $\begin{array}{l}\stackrel{0}{0} \\
\frac{0}{0} \\
\stackrel{0}{\Xi}\end{array}$ & 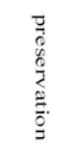 & 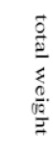 & $\begin{array}{l}\bar{J} \\
\bar{\sigma} \\
\bar{\Xi} \\
0 \\
0\end{array}$ \\
\hline $\begin{array}{l}\text { Weight } \\
\text { value }\end{array}$ & 0.206 & 0.187 & 0.180 & 0.152 & 0.100 & 0.075 & 0.059 & 0.041 & 1 & 0.125 \\
\hline $\begin{array}{l}\text { position in } \\
\text { a name list }\end{array}$ & 1 & 2 & 3 & 4 & 5 & 6 & 7 & 8 & & \\
\hline
\end{tabular}




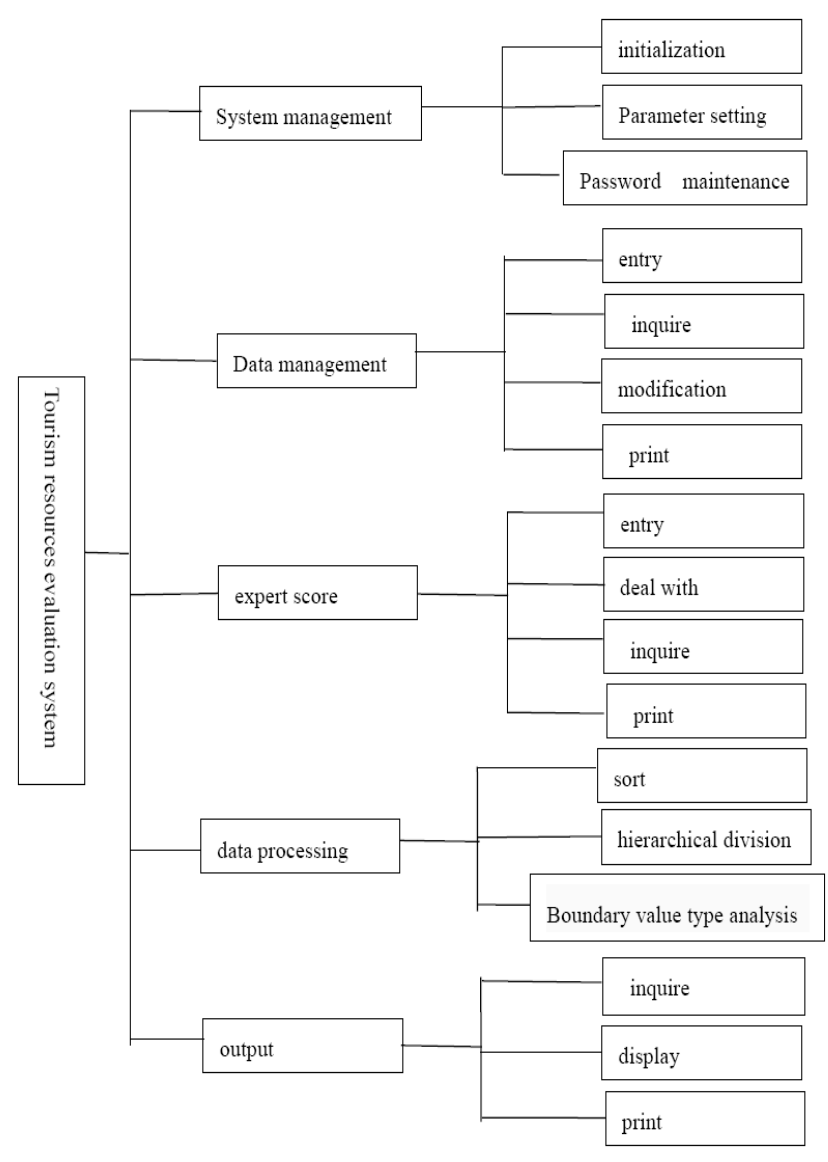

Figure 1 Software structure

\section{THE PRINCIPLE OF FUZZY CLUSTERING ANALYSIS METHOD}

Fuzzy mathematics is a new branch of mathematics, found by L.A. Zadeh in 1965, an American Cybernetics expert. It is used to study and dispose fuzzy phenomenon and fuzzy concept. Cluster analysis is a multivariate analysis method of mathematical statistics, namely using mathematic to quantitatively determine the relationship of samples, and to make sure the sort was objective. Fuzzy mathematics method was introduced into cluster analysis, so that the cluster analysis can better adapt to the fuzziness of the objective world. The basic procedures of fuzzy cluster analysis are as follows:

(1) selecting clustering factors of samples

(2)disposing the data of statistical indexes with Standardized treatment

(3)calculating the similar statistics of the sorted subjects $r_{i j}$,then determine Similar relationship matrix R.

As shown in the figure, $\mathrm{N}$ is the number of the sorted objects

(4)calculating fuzzy equivalence relations $R^{*}$, making $\mathrm{R} \rightarrow \mathrm{R}^{2} \rightarrow \ldots \rightarrow \mathrm{R}^{2 \mathrm{k}}=\mathrm{R}^{*}$.

(5)using different $\lambda$ level to gather fuzzy equivalence relations, and then clustering

$$
\mathrm{R}=\left[\begin{array}{cccc}
r_{11} & r_{12} & \ldots & r_{1 n} \\
r_{21} & r_{22} & \ldots & r_{2 n} \\
\ldots & \ldots & \ldots & \ldots \\
r_{n 1} & r_{n 2} & \ldots & r_{n n}
\end{array}\right]
$$

\section{THE MAIN FUNCTION OF THE SYSTEM}

The system is a system of information management and data analysis which is specifically designed for tourism resources evaluation. Also it has friendly interface and it is powerful. With the help of the system, it is quick and accurate to accomplish tourism resources evaluation, and then get the perfect results.[2]

According to the features of tourism resources evaluation, the system can provide the following functions:

(1) Entering, querying, modifying, and printing the collected data;

(2) entry evaluation results;

(3)Processing the collected data, namely completing tourism resources evaluation, including:

※ranking;

※dividing boundary value levels;

※analyzing boundary value types with the method of fuzzy clustering.

\section{SOFTWARE DESIGN}

The software is programmed by Delphi. The structure diagram of the software system is shown in Figure 1. Brief instructions of the functions and implementation approaches of some modules are as follows:

(1)The module of system management. System management module was used to complete system initialization, password maintenance and parameter setting etc.. In order to improve the flexibility and scalability of the system, we provided a configuration environment in which the operator can set the features of the system (for example dispose sample number), and generate the corresponding database file. When the system booting, first read the files, and then decide the various characteristics of the system according to the content.[3]

(2)The module of data management. The module was used to input, query, modify, and print the collected data. Therefore, at first establish a database which consists of all the information of the original data (questionnaire). Its structure is shown in Table 2. Therefore, tourism resources of each scenic spots are recorded in the database, on which basis, the database can conduct a variety of operations , and accomplish effective management of the original data.[4] 
(3)The module of experts scoring. This module was used to input, query and dispose the scores of each scenic spots which the experts give according to original data. Scores processing can introduce a variety of commonly used filtering techniques to improve the fairness of the results.

(4)The module of data processing. It is the core of the system, which is used to complete tourism resources evaluation, including ranking scenic spots, dividing Boundary value hierarchy, and analyzing boundary values. The module requires a lot of fuzzy mathematics. In order to improve the efficiency of software development, Mature fuzzy math control was adopted, and then optimizing and improving it to make sure the reliability of the system.[5]

(5) The output module of analysis result. The module was used to query, display and print the results of the assessment, the user can set the format of the output text and charts.

\section{CONCLUSION}

The system has been successfully applied to the Chinese National Natural Science Fund "Tourist Attractions Resources Boundary Value System and Its Application", and has achieved good effect in the evaluation of the tourism resources in China. Also, the system has good versatility, and can be applied to other research fields through some modification, for example, to assess human resources and mineral resources etc.

Table 2 Database structure of the investigation table

\begin{tabular}{lllll}
\hline $\begin{array}{l}\text { serial } \\
\text { number }\end{array}$ & field name & type & The width (in bytes) & instructions \\
1 & REF-NUM & N & 5 & Serial number \\
2 & NAME & $\mathrm{C}$ & 30 & $\begin{array}{l}\text { Scenic spot name } \\
\text { Scenic category }\end{array}$ \\
3 & TYPE & $\mathrm{N}$ & 3 & \\
4 & ADDR & $\mathrm{C}$ & 30 & place \\
5 & EVALU1 & $\mathrm{M}$ & & Ancient book record \\
6 & EVALU2 & $\mathrm{M}$ & & Celebrity evaluation \\
7 & EVALU3 & $\mathrm{M}$ & & The evaluation of official and folk \\
8 & EVALU4 & $\mathrm{M}$ & & On-the-spot investigation content \\
9 & SAMP-NAME & $\mathrm{C}$ & 16 & Investigator's name \\
10 & SAMP-DATE & $\mathrm{D}$ & & Date of Survey \\
11 & PICTURE & 0 & & Scenic related images \\
12 & REMARK & $\mathrm{C}$ & 40 & note \\
\hline
\end{tabular}

Over the years, as the important basic conditions for tourism development, tourism resources have been drawing much attention from all the aspects. Although along with the national standard of Classification, Investigation and Evaluation of Tourist Resources (GB/T18972 - 2003) of the People's Republic of China have been putting into practice since May 1, 2003, a set of effective methodologies has been put forward for the quantitative evaluation of the monomer tourism resources, the standard lack guiding role for the comprehensive evaluation of the regional tourism, and the advantages of the tourism resources among the regions are difficult to contrast and apply, causing the negative effects on the tourism industry inevitably. To change this situation, it is necessary to search for practical evaluation index system and methods of regional tourism resources which is based on the monomer tourism resources. The evaluation elements of tourism resources not only includes physiographic conditions, aesthetic value, scientific value, cultural value, and other value etc. of the resources, the Angles of tourists also should be put into consideration, so that the will and requirements of the tourists can be reflected in the development of tourism resources, and only in this way can tourism resources evaluation, tourism product development and tourism marketing be combined organically.[6]

Tourism resources evaluation is a complicated system project, for so many factors that affect evaluation and the very complicated structure. The international evaluation of tourism resources began in the 1960s, visual quality evaluation methods was adopted in the early; In the seventies and eighties of the 20th century, the more systematic, standardized and diverse evaluation models of tourism resources were formed, among which the Travel Cost Method (TCA) and the Hedonic Pricing Method (HPA) are representative ; In the 1990s, Contingent valuation method (CVM) was gradually in the dominant position in evaluation of monetary value of tourism resources. While tourism resources evaluation in China began in late 1980s, mathematical method was introduced by many scholars to evaluate tourism resources. In recent years, fuzzy mathematical method was widely used. Because of the fuzzy and uncertain factors of tourism resources, the better results can be achieved by using fuzzy mathematical method to classify and evaluate resources. Fuzzy clustering is a new evaluation technology developed in the 1970s which adopts fuzzy mathematical method. Fuzzy clustering is also a multivariate techniques which is based on characteristics of the objective things, closeness degree and similarity, and establish fuzzy similar relations through objective things, and conducts clustering analysis by using fuzzy equivalence relation. Fuzzy clustering has overcome the shortcomings of evaluation standard boundary which is too clear, implement the index quantification, the modernization of the evaluation, and the public of the standard assessment, guaranteeing the objective and accuracy of the evaluation results. Therefore, the reasonable results can be achieved and the quantitative relations of fuzziness and randomness which is uncertain economic phenomenon can be better handled. Nowadays fuzzy clustering has been widely 
introduced into the fields of economic planning, weather forecasting, environmental protection etc., and it can also be applied to tourism resources evaluation and the study and development of tourism. Regional tourism resources is the base of tourism development, and to evaluate the tourism resources scientifically is the prerequisite for its development and utilization.[7]

From the process and results of the evaluation, the application of fuzzy clustering in tourism resources evaluation is scientific and feasible. The establishment of evaluation index system of tourism resources and evaluation model of fuzzy clustering mathematical reduce the differences between subjective and objective, and abandoned onesidedness which is based on the subjective impression. Therefore fuzzy clustering improves the accuracy of the tourism resources evaluation, and verify the applicability of the fuzzy clustering evaluation method on the tourism resources. It also has universal guiding significance to evaluation of other fields whose influenced factors are complicated. Certainly, regional tourism resources are a complex system which is formed by resources elements and its process of movement. Tourism development is a comprehensive project about many fields, concerning the departments of society, economy and environment etc.. The occurrence condition of tourism resources is not the only factor which decides the development of regional tourism. The existing basis, regional economic and social conditions, regional natural environment conditions, regional geographical features etc. to a great extent restrict the draw strength, function, development mode, development level and the sequence and so on of the regional tourism resources. The influence and function of these factors in the regional tourism resources will be discussed later.[8]

Evaluation model and fuzzy clustering analysis method introduced to sort and grade the resources can be used to evaluate the tourism resources in the province and the state and the regional status in tourism system. The evaluation method is feasible. Classification, Investigation and Evaluation of Tourist Resources formulated by China National Tourism Administration has been popularized in China in 2003. The research and application of national tourism resources has preliminary already reached the point of order, especially the pilot provinces of Zhejiang and Henan have clear idea of the classification and quantity of the local tourism resources. A set of effective methods system about quantitative evaluation of the monomer tourism resources has been put forward, so that we can quickly to evaluate, sort, store and use monomer tourism resources. The achievement which is rare in the world fills the gaps in China. Starting from the existing basis, using the database of provincial monomer tourism resources, applying this evaluation model, and using fuzzy clustering analysis method to sort and grade resources, and to evaluate the tourism resources in the province and even the state and the regional status in the tourism system. The evaluation method is feasible. The establishments of quantitative evaluation methods of the tourism resources make tourism resources evaluation has more objective and scientific evaluation methods, and also make tourism resources evaluation on a healthy development of standardization, scientific. This method plays a guidance role on evaluation, development, protection and management of the regional tourism resources. Therefore, some research results of this paper be helpful to the comparative study of regional tourism resources.

\section{REFERENCES}

[1] Cheng Wang, Shaohui Liu, Feng Jiang, Yan Liu, A Robust Scalable Spatial Spread-Spectrum Video Watermarking Scheme Based on a Fast Down sampling Method, Journal of Computers, Vol 7, No 9 (2012), 2256-2261.

[2] Yang Xin "medical tourism is becoming a global tourism attraction. Journal of Tourism College of Zhejiang, 2010(3) 19--21.

[3] Wang Yan. Comparison of Basic theory of international health tourism. Techno-economics\& Management Research. 2008(3) 201--205.

[4] Farah Said, Benachenhou Abdelhalim, Neveux Guillaume, Barataud Denis, Design of a Flexible Hardware Interface for Multiple Remote Electronic practical Experiments of Virtual Laboratory, International Journal of Online Engineering (iJOE), Vol 8 (2012), pp. 7-12

[5] Jesús Luis Muros-Cobos, Juan A. Holgado-Terriza, A Componentizable Server-Side Framework for Building Remote and Virtual Laboratories,International Journal of Online Engineering (iJOE), Vol 8 (2012), pp. 43-51

[6] Imran Khan, Dinesh Muthusamy, Waqas Ahmad, Benny Sällberg, Kristian Nilsson, Johan Zackrisson, Ingvar Gustavsson, Lars Håkansson ,Performing Active Noise Control and Acoustic Experiments Remotely, International Journal of Online Engineering (iJOE), Vol 8 (2012), pp. 65-74

[7] Carlos Manuel Paiva, Pedro Nogueira, Gustavo Alves, Arcelina Marques, Pedro Guimarães, Rubem Couto ,A Flexible Online Apparatus for Projectile Launch Experiments,International Journal of Online Engineering (iJOE), Vol 9 (2013),pp. 35-36

[8] Tiago Faustino Andrade, Manuel Rodrigues Quintas, Carlos Moreira Silva, Maria Teresa Restivo, Maria Fátima Chouzal, Teresa Freitas Amaral ,Virtual Instrumentation in Biomedical Equipment,International Journal of Online Engineering (iJOE), Vol 9 (2013),pp. 28-30 